\title{
Inferring Default Correlation from Equity Return Correlation
}

\section{Sheen Liu}

Washington State University, Tri-Cities, Richland, WA, USA

E-mail:liusx@tricity.wsu.edu

\section{Howard Qi}

Michigan Tech University, Houghton, MI, USA

E-mail: howardqi@mtu.edu

\section{Jian Shi}

Fannie Mae, Washington DC, USA

E-mail: jian_shi@fanniemae.com

\section{Yan Alice Xie}

University of Michigan, Dearborn, Dearborn, MI, USA

E-mail: yanxie@umich.edu

\begin{abstract}
This paper presents a new approach for estimating default correlation by linking default correlation to equity return correlation while preserving the fundamental relation between default and asset correlations in the structural framework. Our hybrid model thus overcomes a long-standing empirical difficulty that default correlation estimation relies on the unobservable asset process. The empirical analysis shows that our hybrid model demonstrates a considerable improvement over the existing structural model of Zhou (2001) for the sample periods of 19701993 and 1990-2010. We also illustrate the difference between the two models in predicting default correlations over the period of the 2008 financial crisis.
\end{abstract}

Keywords: Default correlation, equity (return) correlation, defaultable bonds, structural model

JEL classification: G1, G2

We thank an anonymous referee, John Doukas (the editor), Chunchi Wu at the SUNY Buffalo, and participants at the European Financial Management 2009 Symposium on Risk Management in Financial Institutions and the Financial Management Association 2010 Meeting for valuable comments. We also thank the University of Michigan-Dearborn for financial support. Sheen Liu would like to thank the support from the National Science Foundation of China (No. 71071027). The authors are responsible for the contents of the publication. Correspondence: Yan Alice Xie 


\section{Introduction}

Correctly estimating default correlation is critical for credit risk management because portfolio losses depend on joint default events between obligors. Das et al. (2001) find that default rates of debts in credit portfolios are significantly correlated and estimates of credit losses are substantially biased if default correlation is ignored. The recent financial crisis is an acute example underscoring the importance of understanding default correlation. As pointed out by Gorton (2009), the subprime panic that triggered the financial crisis is caused by the lack of information about risks of default loss on a number of interlinked securities, special purpose vehicles, and derivatives, which are all related to subprime mortgages. Jorion (2009) states that the correlation structure used by rating agencies underestimates default correlation, which led to an understatement of the default risk for triple-A tranches of securities backed by subprime mortgages. As a result, many banks that held these securities experienced large losses. Since the extant default correlation models are clearly inadequate, we propose a new method to infer default correlation from equity return correlation using a structural approach to improve model prediction.

At present, the structural model is commonly used by financial researchers and practitioners to estimate default correlation. A major advantage of this type of model is its ability to endogenously generate default probability as well as debt and equity values in a unified framework. A common way to model default correlation using the structural framework is to assume that firms' assets are correlated. Asset values are treated as a function of common factors and firm-specific factors where common factors dictate asset return correlation (asset correlation hereafter) between firms (e.g. Finger, 1999; Zhou, 2001). While the structural approach provides a cohesive framework to relate asset correlation to default correlation, implementation of this type of model faces the problem that the asset value process is actually unobservable. To overcome this problem, Zhou (2001) assumes that asset correlation is equal to equity return correlation (equity correlation hereafter) and picks a constant asset correlation for differently rated bonds. Similarly, the common practice in the financial industry is to use equity correlation as a proxy for asset correlation (see de Servigny and Renault, 2004). However, not only are these solving methods theoretically inaccurate, but even as an approximation, they lack empirical support as well. For example, the empirical study by Lopez (2004) suggests that average asset correlation is a decreasing function of default probability and an increasing function of asset size, which implies that the assumption of constant asset correlation is not valid. de Servigny and Renault (2004) show that equity-driven default correlations are weakly related to empirical default correlations, which suggests that it is questionable to use equity correlation to proxy for asset correlation directly. Furthermore, the literature has documented that the output of portfolio credit risk models is very sensitive to the input of asset correlation (e.g. Gersbach and Lipponer, 2003; Jorion, 2009). Therefore, how to obtain unobservable asset correlation accurately from observable data is a critical issue in the structural approach to predict default correlation between firms.

The new method we propose in this paper tackles this critical issue. Our method first establishes the links between equity correlation and asset correlation and between asset correlation and default correlation, respectively. The two links are then integrated to eliminate the requirement for the information of asset correlation which is unobservable. In this way, we are able to infer default correlation from observed equity correlation reliably based on the structural framework. 
Based on this integrated approach, we develop a hybrid model. The mechanism is that we first adopt a first-passage-time structural model - the Leland and Toft model (1996, hereafter the LT model) and extend it to a two-firm setting in which equity value and default of firms are intrinsically linked. The extended LT model thus links equity correlation to asset correlation. Next, we use Zhou's default correlation model (2001) to link asset correlation to default correlation. We choose Zhou's model because like the LT model, it builds on the first-passage-time framework. Moreover, Zhou's model yields an analytical formula for calculating default correlations based on firm-specific information, thereby easily implemented in a variety of applications. Combining these two structural models yields a direct link between equity and default correlations. We then apply this hybrid model and Zhou's original model to predict pairwise default correlations per class of rating for two sample periods of 1970-1993 and 1990-2010, and compare the model results with empirical estimates of default correlation by Lucas (1995) for 1970-1993 and our own estimations for 1990-2010. ${ }^{1}$

Our results confirm that equity correlation is not a good proxy for asset correlation. In particular, as the time horizon increases and the bond rating deteriorates, the gap between equity and asset correlations widens increasingly.

More importantly, empirical evidence suggests that the hybrid model makes a significant improvement over Zhou's model, especially for pairs of low-rated bonds. For instance, with the sample of 1990-2010, the hybrid model predicts the ten-year default correlation between B-rated bonds to be $36.1 \%$, which is close to our empirical estimate of $32 \%$, while Zhou's model predicts a correlation of $11 \%$. With the earlier sample of 19701993, similar improvement is also observed - given an empirical estimate of 38\%, Zhou's model predicts $13.7 \%$ while the hybrid model predicts $32.3 \%$. The overall results clearly show that the hybrid model outperforms Zhou's model. We also illustrate differences between the two models in predicting default correlations over the period of the 2008 financial crisis when equity correlations fluctuate greatly.

Our paper makes several contributions to the literature and the financial industry. First, our work is the first attempt in the literature to link equity correlation, asset correlation, and default correlation coherently. Our approach is not only theoretically appropriate but also provides better estimates of default correlation without imposing more complex structures such as correlated default boundary, networking, cross holdings among firms (e.g. Giesecke, 2003, 2006), or nonparametric measures of correlation ${ }^{2}$. Second, since the use of equity correlation as the proxy for asset correlation is the standard market assumption (see de Servigny and Renault, 2004), our work provides insightful implications and a way for financial practitioners to improve modelling default correlation and

\footnotetext{
${ }^{1}$ Lucas estimates empirical default correlations using the firm bankruptcy data for the sample period of 1970-1993. In order to directly compare our theoretical predictions to Lucas's empirical results, we implement the models for the same sample period. We also study the latest database (1990-2010) for both model implementation and empirical estimation to ensure that our main results are robust. The lengths of the two sample periods are comparable and suitable to the longest horizon we investigate (20 years). The slight difference in their lengths is solely due to the availability of the data. We thank the anonymous referee for suggesting adopting a more recent sample to extend our analysis.

${ }^{2}$ We thank the anonymous referee for pointing out the use of other dependence measures, which furthers our understanding of default correlation along the direction of this study.
} 
managing financial risk. Third, our up-to-date empirical estimation of default correlations may facilitate theoretical studies in default correlation along this line in future.

The remainder of the paper is organised as follows. Section 2 first estimates empirical default correlations for 1990-2010 in addition to Lucas's results for 1970-1993 as the benchmark for comparison of model performance. Next, empirical estimation of equity correlation is conducted in preparation for implementation of Zhou's model and the hybrid model. Lastly, Zhou's model is applied to predict default correlations for the two sample periods. Section 3 derives an integrated first-time-passage hybrid model and discusses the model implementation and Monte Carlo simulations. Section 4 analyses the calibrated hybrid model and reports the model predictions of default correlation. A thorough analysis of the model performance is then carried out for the hybrid model and Zhou's model using empirical default correlation as the benchmark over the sample periods of 1970-1993 and 1990-2010. The difference between the two models is further illustrated over the period of the 2008 financial crisis. Finally, Section 5 summarises the major findings and concludes the paper.

\section{Default Correlation: Empirical Analysis and Zhou's Model}

\subsection{Empirical estimation of default correlation}

In this section, we empirically estimate default correlations between firms with different levels of default risk (approximated by credit ratings). We follow the method in Lucas (1995) for the sample period of 1990-2010. Specifically, $\rho_{D}$, the default correlation between two ratings is determined by

$$
\rho_{D}=\operatorname{Corr}\left[D_{1}, D_{2}\right]=\frac{P\left[D_{1} \times D_{2}\right]-P\left[D_{1}\right] \times P\left[D_{2}\right]}{\sqrt{P\left[D_{1}\right]\left(1-P\left[D_{1}\right]\right)} \times \sqrt{P\left[D_{2}\right]\left(1-P\left[D_{2}\right]\right)}}
$$

where $D_{1}$ and $D_{2}$ are binary variables for rating categories of 1 and 2 , which take the value of one if the firms are in default and zero otherwise. $P\left[D_{i}\right], i=1,2$ is the default probability of a firm in a given letter rating and $P\left[D_{1} \times D_{2}\right]$ is the joint probability of default between rating categories of 1 and 2 , within a specified time period.

$P\left[D_{i}\right]$ is estimated by dividing the number of default events by the total number of firms in that rating. Specifically, in each year, we first determine the number of default events in a given rating category within a specified time period $T$ (e.g. $4,6,8$ and 10 years). ${ }^{3}$ That is, at each point in time $t$, we look at the time period of $[t, t+T]$. We then sum up the number of default events for the specified time period $T$ during the entire sample period and use it as the numerator. Next, we compute the total number of firms in that rating category within time period $T$ and then sum up over the entire sample period. This is the denominator of $P\left[D_{i}\right]$. If there is a rating change (rather than default) of a certain firm within time period $T$, we exclude this firm from the denominator counting.

The joint probability of default between two ratings, $P\left[D_{1} \times D_{2}\right]$, is estimated similarly. First of all, we pair all possible firms in the rating categories 1 and 2 within time

\footnotetext{
${ }^{3}$ In this study, we only report the results for empirical default correlations and model predicted default correlations for time horizons of $4,6,8$, and 10 years. We also examine other time horizons and the results are qualitatively similar. Other results are available upon request.
} 
period $T$ by drawing one firm each time from each of the two rating categories. The number of pairs is summed over the whole sample period and used as the denominator of $P\left[D_{1} \times D_{2}\right]$. Second, the numerator is determined by counting the number of pairs that both default within the given time period $T$ and summing up over the sample years.

We use the issuer level default data from Moody's Corporate Default Risk Service database to estimate pairwise default correlations per class of rating. Over the sample period of 1990-2010, there are 11,213 unique issuers. To be consistent with our theoretical model, we treat a bankrupt firm emerging from reorganisation as a new firm. ${ }^{4}$ Table 1 lists both Lucas's results (1970-1993) in Panel A as well as our own empirical estimates of default correlation (1990-2010) in Panel B. Compared to Lucas's results, our estimates appear to be more reliable for high-rated bonds. For example, for the Aa-Aa ( $T=4$ years) and the Baa-Baa $(T=4$ and 10 years) pairs, Lucas's default correlations are zeros. In contrast, our estimated default correlation for Aa-Aa ( $T=4$ years) is $1.1 \%$, and for Baa-Baa ( $T=4$ and 10 years) is $2.7 \%$ and $6.3 \%$ respectively. ${ }^{5}$ In general, our results for the updated period (1990-2010) have a similar pattern as that of Lucas (1995) for the earlier period (1970-1993). That is, as time horizon lengthens and credit rating deteriorates, default correlation gets stronger. The empirical default correlations will serve as a benchmark for analysing the performance of Zhou's model and our proposed hybrid model in the later sections.

\subsection{Empirical estimation of equity correlation}

Empirically estimated equity correlation $\rho_{S}$ is a key input variable in both Zhou's model and our hybrid model. We first retrieve monthly stock returns from the CRSP and the data of firm ratings from Compustat. ${ }^{6}$ After excluding firms without the rating information, we end up with 60 (218) Aa-rated firms, 269 (769) A-rated firms, 388 (1,241) Baa-rated firms, $214(1,246)$ Ba-rated firms, and $141(1,093)$ B-rated firms over the sample periods of 1970-1993 (1990-2010) ${ }^{7}$.

We next use monthly stock returns to calculate equity correlations for each year. If there are $n$ firms with the same rating, we will have $n(n-1) / 2$ pairs of correlations within the

\footnotetext{
${ }^{4}$ The reason is that the first-time passage framework assumes bankruptcy as an absorbing barrier and the firm is completely gone forever after it enters into bankruptcy. Moreover, this treatment could allow us to maintain reasonable sample size for different rating categories to migrate estimation errors for default correlation. Note that default correlation is a ratio of two fractions. Small sample size could cause very small fractions, which leads to large estimation errors for default correlation.

${ }^{5}$ de Servigny and Renault (2004) shows that even 1-year default correlations for Aa-Aa and Baa-Baa are not zeros, while they use the data of Standard and Poor's over 1981-2002. Also, they point out that default correlation generally increases with time horizon. Hence, we shed doubt on Lucas's estimates that may be driven by small sample size or too few observations of default events for Aa- and Baa-rated bonds.

${ }^{6}$ Compustat provides both short-term and long-term issuer credit ratings. In our analysis, we limit attention to those firms with assigned Standard \& Poor's Long-Term Domestic Issuer Credit Rating.

${ }^{7}$ The numbers in parentheses are numbers of different rating firms for the period of 1990 to 2010, while the numbers out of parentheses are that for the period of 1970 to 1993.
} 
Table 1

Empirical estimates of default correlation

This table reports the empirical default correlation estimates for different credit ratings over different time horizons. Panel A reports the estimates for the period of 1970-1993 from Lucas (1995). All estimates are in percentages and rounded to whole numbers by Lucas (1995). Panel B reports the estimates for the period of 1990-2010. The estimates are calculated based on Moody's Corporate Default Risk Service database by following the similar methodology in Lucas (1995). All estimates are in percentages and rounded to one decimal. Time horizons reported are 4, 6, 8 and 10 years.

Panel A: Sample period 1970-1993

\begin{tabular}{|c|c|c|c|c|c|c|c|c|c|c|}
\hline & & & $=4 y$ & & & & & $=6 \mathrm{y}$ & & \\
\hline & $\mathrm{Aa}$ & A & Baa & $\mathrm{Ba}$ & B & $\mathrm{Aa}$ & A & Baa & $\mathrm{Ba}$ & B \\
\hline $\mathrm{Aa}$ & 0 & & & & & 1 & & & & \\
\hline A & 1 & 1 & & & & 1 & 1 & & & \\
\hline Baa & 1 & 1 & 0 & & & 1 & 1 & 0 & & \\
\hline $\mathrm{Ba}$ & 2 & 3 & 3 & 13 & & 3 & 4 & 3 & 15 & \\
\hline B & 2 & 4 & 5 & 22 & 27 & 4 & 7 & 7 & 25 & 29 \\
\hline & & & $=8 y$ & & & & & $=10 \mathrm{y}$ & & \\
\hline & $\mathrm{Aa}$ & $\mathrm{A}$ & Baa & $\mathrm{Ba}$ & $\mathrm{B}$ & $\mathrm{Aa}$ & A & Baa & $\mathrm{Ba}$ & $\mathrm{B}$ \\
\hline $\mathrm{Aa}$ & 0 & & & & & 1 & & & & \\
\hline A & 1 & 2 & & & & 2 & 2 & & & \\
\hline Baa & 1 & 1 & 0 & & & 1 & 1 & 0 & & \\
\hline $\mathrm{Ba}$ & 3 & 5 & 2 & 10 & & 3 & 4 & 2 & 8 & \\
\hline B & 5 & 11 & 7 & 23 & 37 & 8 & 9 & 6 & 17 & 38 \\
\hline
\end{tabular}

Panel B: Sample period 1990-2010

\begin{tabular}{|c|c|c|c|c|c|c|c|c|c|c|}
\hline & \multicolumn{5}{|c|}{$T=4$ years } & \multicolumn{5}{|c|}{$T=6$ years } \\
\hline & $\mathrm{Aa}$ & A & $\mathrm{Baa}$ & $\mathrm{Ba}$ & $\mathrm{B}$ & $\mathrm{Aa}$ & A & Baа & $\mathrm{Ba}$ & $\mathrm{B}$ \\
\hline $\mathrm{Aa}$ & 1.1 & & & & & 1.1 & & & & \\
\hline A & 1.2 & 2.1 & & & & 1.1 & 1.5 & & & \\
\hline $\mathrm{Baa}$ & 1.6 & 2.5 & 2.7 & & & 1.4 & 1.7 & 3.2 & & \\
\hline $\mathrm{Ba}$ & 2.6 & 3.2 & 3.5 & 7.4 & & 2.4 & 2.5 & 4.7 & 10.0 & \\
\hline \multirow[t]{3}{*}{ B } & 3.4 & 4.5 & 5.3 & 10.5 & 17.0 & 4.8 & 4.3 & 7.4 & 13.8 & 22.3 \\
\hline & \multicolumn{5}{|c|}{$T=8$ years } & \multicolumn{5}{|c|}{$T=10$ years } \\
\hline & $\mathrm{Aa}$ & A & Baa & $\mathrm{Ba}$ & $\mathrm{B}$ & $\mathrm{Aa}$ & A & $\mathrm{Baa}$ & $\mathrm{Ba}$ & $\mathrm{B}$ \\
\hline $\mathrm{Aa}$ & 1.2 & & & & & 1.8 & & & & \\
\hline A & 1.3 & 2.2 & & & & 2 & 3.9 & & & \\
\hline Baa & 1.6 & 3.2 & 5.4 & & & 2.6 & 5.0 & 6.3 & & \\
\hline $\mathrm{Ba}$ & 3.1 & 3.6 & 6.6 & 13.3 & & 3.4 & 6.2 & 9.1 & 17.3 & \\
\hline B & 3.5 & 5.4 & 9.9 & 16.2 & 26.7 & 4.1 & 10.8 & 11.4 & 20.2 & 32.0 \\
\hline
\end{tabular}


rating in a given year. If there are $n$ firms with one rating and $m$ firms with another rating, we will have $n \times m$ pairs of correlations across the two ratings. We calculate pairwise equity correlations within and across ratings each year over the periods of 1970-1993 and 1990-2010. Lastly, we calculate average equity correlations for each rating pair over the two sample periods. The statistics of estimated equity correlations are reported in Table 2 . The means of estimated equity correlations show that equity correlation is generally higher between firms with the same rating (see Panels A-2 and B-2). As the ratings of two firms depart, their equity correlations tend to decline. Given the empirical estimates of equity correlation $\rho_{S}$, we are ready to implement Zhou's model.

\subsection{Application of Zhou's model}

Zhou's (2001) default correlation model is described in the Appendix. ${ }^{8}$ Using Zhou's assumption that asset correlation equals equity correlation, $\rho=\rho_{S}$, and letting $\rho_{S}$ take our empirically estimated equity correlations, we obtain the predicted default correlations by Zhou's model. The results are listed in Table 3 with Panel A for 1970-1993 and Panel B for 1990-2010. The analyses based on the different sample periods suggest the same problem with Zhou's model (2001) as discussed below.

Comparing the predicted default correlations by Zhou's model in Table 3 with the empirical default correlations in Table 1, we find that Zhou's model tends to underpredict default correlations, especially for risky bonds. Take the pair of B-B with $T=10$ years as an example. Zhou's model predicts $13.7 \%$ (11\%) while the actual empirical default correlation yields 38\% (32\%) for 1970-1993 (1990-2010). For the pair of B-A with $T=10$ years, the model predicts $4.4 \%(2.9 \%)$ and the empirical correlation is $9 \%$ (10.8\%) for 1970-1993 (1990-2010). In most cases of high-rated pairs, underprediction also prevails. The systematic underprediction of default correlations by Zhou's model calls for great attention because underpredicted default correlations could lead to understatement of default rates of credit portfolios. As the market moves in an unfavourable direction, the credit portfolios may suffer big losses. The consequence would be more severe for low-rated debts in the portfolio. In the next section, we intend to figure out why Zhou's model systematically underestimates default correlations. Furthermore, we develop a new framework, the hybrid model, to greatly improve the prediction of default correlations.

\section{The Hybrid Model: Theoretical Setup and Simulation}

In Zhou's (2001) work, he uses observable equity correlation to substitute for unobservable asset correlation in implementing his default correlation model. Intuitively, for firms with the low leverage, the asset process and the equity process are close and equity correlation may be an appropriate approximation for asset correlation. However, in the risky bond domain, leverage tends to be high and equity correlation may not be a valid approximation for asset correlation any more. Lopez (2004), de Servigny and Renault (2004) and our results in Section 4.1 confirm this intuition. As such, the systematic

\footnotetext{
${ }^{8}$ For details of the implementation procedure and the derivations of the model, see Zhou (2001).
} 
Table 2

Empirical estimates of equity correlation

This table reports the statistics of empirical estimates of equity correlation for the sample periods of 1970-1993 and 1990-2010, respectively. Panels A-1 and B-1 report the minimum, maximum, the first quantile, and the third quantile of equity correlations between different rating firms. Equity correlations are calculated based on monthly stock returns of different rating firms over the sample periods. Panels A-2 and B-2 report the mean (in percentage) and standard errors (in parentheses) of equity correlations between different rating firms.

Panel A-1: Summary statistics of equity correlations for 1970-1993

\begin{tabular}{lccrrrr}
\hline Rating1 & Rating2 & No. of Observations & Min & Max & Q1 & Q3 \\
\hline Aa & Aa & 21,348 & -0.90 & 0.97 & 0.04 & 0.51 \\
Aa & $\mathrm{A}$ & 99,144 & -0.99 & 0.99 & 0.03 & 0.50 \\
$\mathrm{Aa}$ & $\mathrm{Baa}$ & 133,420 & -0.97 & 0.99 & 0.02 & 0.48 \\
$\mathrm{Aa}$ & $\mathrm{Ba}$ & 65,292 & -0.89 & 0.98 & -0.01 & 0.46 \\
$\mathrm{Aa}$ & $\mathrm{B}$ & 36,795 & -0.96 & 0.98 & -0.02 & 0.47 \\
$\mathrm{~A}$ & $\mathrm{~A}$ & 478,221 & -0.98 & 0.99 & 0.04 & 0.50 \\
$\mathrm{~A}$ & $\mathrm{Ba}$ & 646,946 & -0.97 & 0.99 & 0.02 & 0.49 \\
$\mathrm{~A}$ & $\mathrm{Ba}$ & 319,887 & -0.98 & 1.00 & 0.00 & 0.47 \\
$\mathrm{~A}$ & $\mathrm{~B}$ & 182,209 & -0.98 & 0.99 & 0.00 & 0.48 \\
$\mathrm{Baa}$ & $\mathrm{Baa}$ & 728,526 & -0.99 & 1.00 & 0.01 & 0.48 \\
$\mathrm{Baa}$ & $\mathrm{Ba}$ & 365,471 & -0.97 & 0.99 & -0.01 & 0.46 \\
$\mathrm{Baa}$ & $\mathrm{B}$ & 205,840 & -0.97 & 1.00 & -0.01 & 0.47 \\
$\mathrm{Ba}$ & $\mathrm{Ba}$ & 176,547 & -0.99 & 0.99 & -0.01 & 0.46 \\
$\mathrm{Ba}$ & $\mathrm{B}$ & 100,141 & -0.93 & 0.99 & 0.00 & 0.48 \\
$\mathrm{~B}$ & $\mathrm{~B}$ & 63,932 & -0.90 & 0.98 & 0.01 & 0.48 \\
\hline
\end{tabular}

Panel B-1: Summary statistics of equity correlations for 1990-2010

\begin{tabular}{lcrrrrr} 
Rating1 & Rating2 & No. of Observations & Min & Max & Q1 & Q3 \\
\hline $\mathrm{Aa}$ & $\mathrm{Aa}$ & 54,363 & -0.97 & 0.99 & -0.05 & 0.50 \\
$\mathrm{Aa}$ & $\mathrm{A}$ & 429,863 & -0.99 & 0.99 & -0.06 & 0.49 \\
$\mathrm{Aa}$ & $\mathrm{Baa}$ & 581,864 & -0.99 & 1.00 & -0.07 & 0.48 \\
$\mathrm{Aa}$ & $\mathrm{Ba}$ & 410,949 & -0.99 & 0.99 & -0.10 & 0.46 \\
$\mathrm{Aa}$ & $\mathrm{B}$ & 280,991 & -1.00 & 0.99 & -0.14 & 0.44 \\
$\mathrm{~A}$ & $\mathrm{~A}$ & 867,894 & -0.99 & 1.00 & -0.06 & 0.49 \\
$\mathrm{~A}$ & $\mathrm{Baa}$ & $2,435,341$ & -1.00 & 1.00 & -0.06 & 0.49 \\
$\mathrm{~A}$ & $\mathrm{Ba}$ & $1,714,116$ & -1.00 & 1.00 & -0.08 & 0.47 \\
$\mathrm{~A}$ & $\mathrm{~B}$ & $1,161,628$ & -1.00 & 1.00 & -0.12 & 0.45 \\
$\mathrm{Baa}$ & $\mathrm{Baa}$ & $1,776,179$ & -1.00 & 1.00 & -0.06 & 0.49 \\
$\mathrm{Baa}$ & $\mathrm{Ba}$ & $2,511,991$ & -0.99 & 1.00 & -0.07 & 0.48 \\
$\mathrm{Baa}$ & $\mathrm{B}$ & $1,708,902$ & -0.99 & 1.00 & -0.10 & 0.46 \\
$\mathrm{Ba}$ & $\mathrm{Ba}$ & 893,799 & -0.99 & 1.00 & -0.06 & 0.49 \\
$\mathrm{Ba}$ & $\mathrm{B}$ & $1,220,523$ & -1.00 & 1.00 & -0.09 & 0.48 \\
$\mathrm{~B}$ & $\mathrm{~B}$ & 418,767 & -0.99 & 1.00 & -0.08 & 0.48 \\
\hline
\end{tabular}


Table 2

Continued.

Panel A-2: Mean correlations and standard errors for 1970-1993

\begin{tabular}{|c|c|c|c|c|c|}
\hline & $\mathrm{Aa}$ & A & Baa & $\mathrm{Ba}$ & $\mathrm{B}$ \\
\hline Aa & $\begin{array}{c}25.83 \\
(0.0022)\end{array}$ & & & & \\
\hline A & $\begin{array}{c}25.05 \\
(0.0007)\end{array}$ & $\begin{array}{c}25.8 \\
(0.0005)\end{array}$ & & & \\
\hline $\mathrm{Baa}$ & $\begin{array}{c}23.46 \\
(0.0006)\end{array}$ & $\begin{array}{c}24.32 \\
(0.0003)\end{array}$ & $\begin{array}{c}23.21 \\
(0.0004)\end{array}$ & & \\
\hline $\mathrm{Ba}$ & $\begin{array}{c}21.86 \\
(0.0009)\end{array}$ & $\begin{array}{c}23.13 \\
(0.0004)\end{array}$ & $\begin{array}{c}21.89 \\
(0.0004)\end{array}$ & $\begin{array}{c}21.93 \\
(0.0008)\end{array}$ & \\
\hline \multirow[t]{3}{*}{ B } & $\begin{array}{c}21.24 \\
(0.0012)\end{array}$ & $\begin{array}{c}23.01 \\
(0.0006)\end{array}$ & $\begin{array}{c}21.75 \\
(0.0005)\end{array}$ & $\begin{array}{c}22.36 \\
(0.0007)\end{array}$ & $\begin{array}{c}23.14 \\
(0.0013)\end{array}$ \\
\hline & \multicolumn{5}{|c|}{ Panel B-2: Mean correlations and standard errors for $1990-2010$} \\
\hline & $\mathrm{Aa}$ & A & Baa & $\mathrm{Ba}$ & $\mathrm{B}$ \\
\hline $\mathrm{Aa}$ & $\begin{array}{c}21.18 \\
(0.0016)\end{array}$ & & & & \\
\hline A & $\begin{array}{c}20.17 \\
(0.0006)\end{array}$ & $\begin{array}{c}20.28 \\
(0.0004)\end{array}$ & & & \\
\hline $\mathrm{Baa}$ & $\begin{array}{c}19.26 \\
(0.0005)\end{array}$ & $\begin{array}{c}19.88 \\
(0.0002)\end{array}$ & $\begin{array}{c}20.47 \\
(0.0003)\end{array}$ & & \\
\hline $\mathrm{Ba}$ & $\begin{array}{c}16.89 \\
(0.0006)\end{array}$ & $\begin{array}{c}18.05 \\
(0.0003)\end{array}$ & $\begin{array}{c}19.26 \\
(0.0002)\end{array}$ & $\begin{array}{c}19.88 \\
(0.0004)\end{array}$ & \\
\hline $\mathrm{B}$ & $\begin{array}{c}13.96 \\
(0.0007)\end{array}$ & $\begin{array}{c}15.16 \\
(0.0004)\end{array}$ & $\begin{array}{c}16.99 \\
(0.0003)\end{array}$ & $\begin{array}{c}18.31 \\
(0.0003)\end{array}$ & $\begin{array}{c}18.70 \\
(0.0006)\end{array}$ \\
\hline
\end{tabular}

underestimation of default correlations by Zhou's model may be driven by the use of this inappropriate approximation.

In this section, we set out to determine a more accurate relation between equity correlation and asset correlation by extending the LT model into a two-firm setting. Then we calibrate the extended LT model to obtain asset correlations by letting equity correlations match our empirical equity correlations given in Table 2, and finally we apply Zhou's model to estimate default correlations using the calibrated asset correlations as the input. The foregoing steps constitute our hybrid model.

\subsection{The LT model and the extension into a two-firm setting}

There are a few reasons for us to choose extending the LT model. First, it models bankruptcy as a first-passage-time stochastic process which is a significant improvement over other mainstream term structure models such as the Merton (1974) model. This modelling of bankruptcy is also consistent with Zhou's (2001) model. Second, the LT model also considers both bankruptcy costs and corporate taxes, which is closer to reality. 
Table 3

Default correlation predicted by Zhou's (2001) Model

This table reports the performance of Zhou's (2001) model in estimating default correlation $\rho_{D}$ (in percentage) for different credit ratings over different time horizons for the periods of 1970-1993 and 1990-2010, respectively. Zhou's model assumes that asset correlation equals equity correlation, i.e., $\rho=\rho_{S}$ with equity correlation $\rho_{S}$ given in Table 2, Panels A-2 and B-2. Time horizons reported are 4, 6, 8 and 10 years.

Panel A: Sample period 1970-1993

\begin{tabular}{|c|c|c|c|c|c|c|c|c|c|c|}
\hline & \multicolumn{5}{|c|}{$T=4$ years } & \multicolumn{5}{|c|}{$T=6$ years } \\
\hline & $\mathrm{Aa}$ & A & Baa & $\mathrm{Ba}$ & $\mathrm{B}$ & $\mathrm{Aa}$ & $\mathrm{A}$ & $\mathrm{Baa}$ & $\mathrm{Ba}$ & $\mathrm{B}$ \\
\hline $\mathrm{Aa}$ & 0.0 & & & & & 0.3 & & & & \\
\hline A & 0.1 & 0.2 & & & & 0.5 & 1.0 & & & \\
\hline Baa & 0.1 & 0.4 & 0.9 & & & 0.7 & 1.5 & 2.7 & & \\
\hline $\mathrm{Ba}$ & 0.2 & 0.6 & 2.0 & 6.9 & & 0.9 & 2.1 & 4.3 & 9.4 & \\
\hline \multirow[t]{3}{*}{ B } & 0.1 & 0.6 & 2.0 & 8.8 & 13.0 & 0.7 & 1.8 & 4.1 & 10.6 & 13.6 \\
\hline & \multicolumn{5}{|c|}{$T=8$ years } & \multicolumn{5}{|c|}{$T=10$ years } \\
\hline & $\mathrm{Aa}$ & A & $\mathrm{Baa}$ & $\mathrm{Ba}$ & $\mathrm{B}$ & $\mathrm{Aa}$ & $\mathrm{A}$ & $\mathrm{Baa}$ & $\mathrm{Ba}$ & $\mathrm{B}$ \\
\hline $\mathrm{Aa}$ & 1.0 & & & & & 1.9 & & & & \\
\hline A & 1.4 & 2.2 & & & & 2.5 & 3.6 & & & \\
\hline $\mathrm{Baa}$ & 1.7 & 3.0 & 4.5 & & & 2.9 & 4.5 & 6.1 & & \\
\hline $\mathrm{Ba}$ & 1.9 & 3.7 & 6.1 & 10.8 & & 3.0 & 5.1 & 7.5 & 11.6 & \\
\hline B & 1.6 & 3.2 & 5.7 & 11.5 & 13.7 & 2.5 & 4.4 & 6.9 & 12.0 & 13.7 \\
\hline
\end{tabular}

Panel B: Sample period 1990-2010

\begin{tabular}{|c|c|c|c|c|c|c|c|c|c|c|}
\hline & \multicolumn{5}{|c|}{$T=4$ years } & \multicolumn{5}{|c|}{$T=6$ years } \\
\hline & $\mathrm{Aa}$ & A & Ваa & $\mathrm{Ba}$ & $\mathrm{B}$ & $\mathrm{Aa}$ & A & $\mathrm{Baa}$ & $\mathrm{Ba}$ & $\mathrm{B}$ \\
\hline $\mathrm{Aa}$ & 0.0 & & & & & 0.2 & & & & \\
\hline A & 0.0 & 0.1 & & & & 0.3 & 0.6 & & & \\
\hline $\mathrm{Baa}$ & 0.1 & 0.2 & 0.7 & & & 0.5 & 1.1 & 2.2 & & \\
\hline $\mathrm{Ba}$ & 0.1 & 0.4 & 1.6 & 6.1 & & 0.6 & 1.5 & 3.6 & 8.4 & \\
\hline \multirow[t]{3}{*}{ B } & 0.1 & 0.4 & 1.5 & 7.1 & 10.4 & 0.5 & 1.2 & 3.2 & 8.6 & 10.9 \\
\hline & \multicolumn{5}{|c|}{$T=8$ years } & \multicolumn{5}{|c|}{$T=10$ years } \\
\hline & $\mathrm{Aa}$ & A & Ваa & $\mathrm{Ba}$ & $\mathrm{B}$ & $\mathrm{Aa}$ & A & Baa & $\mathrm{Ba}$ & $\mathrm{B}$ \\
\hline $\mathrm{Aa}$ & 0.6 & & & & & 1.3 & & & & \\
\hline A & 0.9 & 1.5 & & & & 1.7 & 2.5 & & & \\
\hline Baa & 1.3 & 2.2 & 3.8 & & & 2.2 & 3.4 & 5.2 & & \\
\hline $\mathrm{Ba}$ & 1.4 & 2.7 & 5.3 & 9.7 & & 2.3 & 3.9 & 6.5 & 10.5 & \\
\hline B & 1.1 & 2.1 & 4.4 & 9.4 & 11.0 & 1.7 & 2.9 & 5.4 & 9.8 & 11.0 \\
\hline
\end{tabular}


The firm's asset process $V_{t}$ is assumed to follow a drifting geometric Brownian motion. Specifically, $V_{t}$ is characterised by the following continuous diffusion process: ${ }^{9}$

$$
\frac{d V_{t}}{V_{t}}=\left[\mu_{t}(V)-\delta\right] d t+\sigma d Z_{t}
$$

where $\mu_{t}(V)$ is the expected rate of return on the firm's assets, $\delta$ is the payout, which is the proportion of the firm value paid to all security holders, $\sigma$ is the constant volatility of asset returns, and $Z_{t}$ is a standard Wiener process. The asset value $V_{t}$ includes the net cash flows generated by the firm's activities.

Suppose that there is an identical but levered firm issuing a risky debt $d$ per unit time with $t$ periods to maturity, a continuous constant coupon flow $c(t)$ and a principal $P(t)$. The firm remains solvent until the asset value $V_{t}$ hits a default boundary $V_{B}$. Upon bankruptcy, bondholders receive a fraction $\chi=(1-\beta)$ of the asset value $V_{B}$, where $\beta$ is the bankruptcy cost ratio and $\beta V_{B}$ is loss due to bankruptcy. Further, we assume that $r$ represents the continuous interest rate paid by a default-free asset and that investors follow a buy-and-hold investment strategy. Under the risk-neutral valuation, it can be shown that the value of the debt flow, $d$, is given by

$$
d\left(V, V_{B}, t\right)=\frac{c(t)}{r}+e^{-n}\left[p(t)-\frac{c(t)}{r}\right](1-F(t))+\left[\chi V_{B}-\frac{c(t)}{r}\right] G(t),
$$

where $F(t)$ and $G(t)$ are given in Leland and Toft (1996). The total outstanding debt $D$ is the integration of the debt flow $d\left(V, V_{B}, t\right)$ over $T$, the maturity of newly issued debt:

$$
D\left(V, V_{B}, T\right)=\int_{t-0}^{T} d\left(V, V_{B}, t\right) d t
$$

The integral can be carried out numerically. The tradeoff between the benefit of tax shields and bankruptcy costs suggests that there exists an endogenously determined bankruptcy threshold $V_{B}$ that maximises firm value. The equity value, as a function of default boundary $V_{B}$ and asset value $V$, is given by,

$$
S\left(V, V_{B}, T\right)=V+\tau_{c} \frac{C}{r}\left[1-\left(\frac{V_{B}}{V}\right)^{a+z}\right]-\beta V_{B}\left(\frac{V_{B}}{V}\right)^{a+z}-D\left(V, V_{B}, T\right),
$$

where $C$ is the annual coupon payment, and $x_{c}$ is the corporate income tax rate. Parameters $a$ and $z$ are functions of asset volatility $\sigma$ and interest rate $r .{ }^{10}$

\footnotetext{
${ }^{9}$ A similar specification is used by Leland and Toft (1996), Merton (1974), Black and Cox (1976), and Brennan and Schwartz (1978). To simplify the notation, we drop the subscript in $V_{t}$ and understand that $V$ is a function of time $t$ in later Equations. This would avoid confusion with $V_{B}$ as the endogenous default boundary, and $V_{1}$ and $V_{2}$ as the asset processes of firms 1 and 2 .

${ }^{10}$ Detailed derivations of Equations (3) and (5) are given by Leland and Toft (1996).
} 
Equation (5) establishes a link between asset process $V$ and equity process $S$. If asset value $V(t)$ follows a geometric Brownian motion, equity value $S(V)$ as a function of $V(t)$ will also exhibit a similar stochastic process.

To extend the LT model into a two-firm setting, we consider two firms with asset values $V_{1}$ and $V_{2}$. The dynamics of $V_{1}, V_{2}, S\left(V_{1}\right)$, and $S\left(V_{2}\right)$ are specified by Equations (2) to (5). Asset returns $\Delta \ln V_{1}$ and $\Delta \ln V_{2}$ are correlated with a coefficient $\rho$, and have volatilities $\sigma_{1}$ and $\sigma_{2}$. We define equity correlation $\rho_{S}$ as

$$
\rho_{s}=\frac{\operatorname{cov}\left(\Delta \ln S\left(V_{1}\right), \Delta \ln S\left(V_{2}\right)\right)}{\sqrt{\operatorname{var}\left(\Delta \ln S\left(V_{1}\right)\right) \operatorname{var}\left(\Delta \ln S\left(V_{2}\right)\right)}} .
$$

A correlation between two asset processes, $V_{1}$ and $V_{2}$, will undoubtedly lead to a correlation between two corresponding equity processes, $S\left(V_{1}\right)$ and $S\left(V_{2}\right)$. However, these two correlations can diverge significantly because as time evolves, both leverage ratio and asset volatility change. In general, when a firm uses debt, equity and debt do not necessarily move in tandem. This can be seen from the option perspective where equity can be viewed as a call option on a firm's underlying assets, and debt as a shorted put plus a constant. When asset volatility increases, the equity value tends to go up while the debt value can move in an opposite direction. When corporate taxes are considered, the debt-equity movements can be further distorted. ${ }^{11}$ This is why substituting equity correlation $\rho_{S}$ for asset correlation $\rho$ can be problematic, especially for lower ratings.

\subsection{Model implementations: calibration and Monte Carlo simulation}

Using the extended LT model to perform simulations and empirical analysis, we choose interest rate $r=8 \%$ and payout $\delta=6 \%$ for 1970-1993. These figures are in line with Huang and Huang (2003) for the similar time period. For the sample of 1990-2010, we choose interest rate $r=4 \%$ and payout $\delta=2 \% .{ }^{12}$ Corporate tax rate $\tau_{C}$ is set at $35 \%$ and the bankruptcy ratio $\beta$ is set at $20 \%$ of the going concern value right before the default based on the estimates in Andrade and Kaplan (1998). ${ }^{13}$

To implement the extended LT model properly, a calibration is necessary. The objective of calibration is to choose the equity premium and asset volatility $\sigma$ such that the model generates a default probability consistent with the observed default rate for each rating. In Table 4, we list 10-year default rates in Panel A-1 for 1970-1993 and in Panel B1 for 1990-2010. The equity premiums for ratings Aa to B are given in Panels A-2 and B-2 for the two different sample periods, respectively. Since we are dealing with multiple time

\footnotetext{
${ }^{11}$ We note that the extended LT model considers corporate taxes while Zhou (2001) does not. The effect of corporate taxes on debt and equity is not linear because of differential treatments for capital gains tax rate, ordinary income tax rate, and tax rebate due to default losses.

${ }^{12}$ The interest rate is the average of 1-month T-bill rates and the payout is calculated based on the average payout ratio for the S\&P 500 companies over the period of 1990-2010. We find that the model predicted default correlations are not as sensitive to the choices of these two values as the value of equity correlation.

${ }^{13}$ Personal tax rate is set to zero in this simulation. We have also tested various personal tax rates. For the issues discussed in this study, a non-zero personal tax rate does not qualitatively change our results. For simplicity and clarity, we abstract away from personal tax influence. Nevertheless, personal taxes will be the subject of a sequel to this study.
} 
Table 4

Calibration parameters for the extended LT model

This table reports the calibration parameters for the extended Leland-Toft (LT) model that is used to estimate asset correlation from equity correlation. Panels A-1 and B-1 report historical cumulative default rates (in percentage) for bonds with different ratings over different time horizons for the sample periods of 1970-1993 and 1990-2010, respectively. The cumulative default rates for 1970-1993 are from Fons (1994) and that for 1990-2010 are computed from annual default rates provided by the Standard \& Poor's 2010 Annual Global Corporate Default Study and Transition Matrix, published on March 31, 2011. Panels A-2 and B-2 report equity premiums and implied asset volatilities (in percentages) for different rating bonds for the sample periods of 1970-1993 and 1990-2010, respectively. Equity premiums are defined as the rating-based average stock return in excess of the yield of Treasury bill. Equity premiums for 1970-1993 are from Bhandari (1988) and that for 1990-2010 are computed based on the monthly stock returns reported in the CRSP for a similar time period. Implied asset volatilities $\sigma$ for various rating categories over two sample periods are obtained by calibrating the extended LT model against the historical cumulative default rates in Panels A-1 and B-1, respectively. Equation (7) is used to determine $\sigma$ which minimises the model predicted default probability and the observed default rates listed in Panels A-1 and B-1.

\begin{tabular}{lccccc}
\hline \multicolumn{5}{c}{ Panel A-1: Historical cumulative default rates for $1970-1993$} & \\
\hline$T$ (years) & Aa & A & Baa & Ba & B \\
\hline 1 & 0.02 & 0.01 & 0.16 & 1.79 & 8.31 \\
2 & 0.04 & 0.09 & 0.51 & 4.38 & 14.85 \\
3 & 0.08 & 0.28 & 0.91 & 6.92 & 20.38 \\
4 & 0.20 & 0.46 & 1.46 & 9.41 & 24.78 \\
5 & 0.32 & 0.62 & 1.97 & 11.85 & 28.38 \\
6 & 0.43 & 0.83 & 2.46 & 13.78 & 31.88 \\
7 & 0.52 & 1.06 & 3.09 & 15.33 & 34.32 \\
8 & 0.64 & 1.31 & 3.75 & 16.75 & 36.71 \\
9 & 0.76 & 1.61 & 4.39 & 18.14 & 38.38 \\
10 & 0.91 & 1.96 & 4.96 & 19.48 & 39.96 \\
\hline
\end{tabular}

Panel B-1: Historical cumulative default rates for 1990-2010

\begin{tabular}{lccccc}
$T$ (years) & Aa & A & Baa & Ba & B \\
\hline 1 & 0.02 & 0.08 & 0.25 & 2.86 & 7.05 \\
2 & 0.04 & 0.16 & 0.50 & 5.30 & 13.46 \\
3 & 0.06 & 0.24 & 0.72 & 7.56 & 18.67 \\
4 & 0.06 & 0.30 & 0.92 & 10.08 & 23.85 \\
5 & 0.07 & 0.38 & 1.17 & 12.61 & 28.98 \\
6 & 0.09 & 0.46 & 1.45 & 15.32 & 34.21 \\
7 & 0.10 & 0.55 & 1.75 & 18.11 & 39.48 \\
8 & 0.12 & 0.65 & 2.08 & 21.01 & 44.69 \\
9 & 0.14 & 0.77 & 2.37 & 23.69 & 49.36 \\
10 & 0.16 & 0.88 & 2.63 & 25.99 & 53.29 \\
\hline
\end{tabular}

(Continued) 
Table 4

Continued.

Panel A-2: Other parameters for 1970-1993

\begin{tabular}{lcclrr} 
& Aa & A & Baa & Ba & B \\
\hline Equity premium & 5.6 & 5.99 & 6.55 & 7.3 & 8.8 \\
Implied asset volatility $\sigma$ & 3.4 & 3.8 & 9.5 & 23.3 & 42.9 \\
\hline
\end{tabular}

Panel B-2: Other parameters for 1990-2010

\begin{tabular}{llllll} 
& Aa & A & Baa & Ba & B \\
\hline Equity premium & 0.94 & 0.94 & 0.99 & 1.20 & 1.92 \\
Implied asset volatility $\sigma$ & 2.8 & 3.2 & 3.7 & 10.7 & 28.4 \\
\hline
\end{tabular}

horizons, from one to ten years in the present case, we carry out the model calibration by choosing an asset volatility $\sigma$ that minimises the squared difference of log odds between the implied and observed default probabilities, ${ }^{14}$

$$
\sigma=\arg \min _{\sigma \geq 0} \sum_{i-1}^{10}\left[\ln P_{i}(\sigma)-\ln P_{i}\right]^{2},
$$

where $P_{i}$ is the model-implied default probability by year $i$, and $P_{i}$ is the corresponding observed default rate. Since we input equity premiums into the model, these probabilities are physical probabilities. The model-implied asset volatility $\sigma$ for the various bond ratings are reported in Panels A-2 and B-2 of Table 4. To value debt and equity with the model, we return to the risk-neutral measure by retaining asset return volatility $\sigma$ and forcing equity premium to zero as required by the equivalent martingale measure approach.

In Monte Carlo simulations, for each iteration we generate a time-series sample path according to Equation (2) with the starting asset value $V_{i}(0)$ normalised to 100 , where $i=1,2$ denoting the two firms. For each random movement in $V_{i}(0)$ at time $t$, we apply Equations (3) to (5) to obtain debt value $D_{i}(t)$ and equity value $S_{i}(t)$. For the next random movement in $V_{i}(t+\Delta t)$ at time $t+\Delta t$, we again apply the model to obtain $D_{i}(t+\Delta t)$ and $S_{i}(t+\Delta t)$ while keeping the coupon, principal and default boundary unchanged. This is to recognise the fact that the stationary capital structure of the LT model rules out any debt restructuring after the optimisation is done. The procedure is repeated until we reach the horizon at $t=T$. This allows us to map out one sample path. For a second iteration, the same procedure is repeated to generate another sample path of $V_{i}(t)$ (and thereby $D_{i}(t)$ and $S_{i}(t)$ as well) for each firm.

\footnotetext{
${ }^{14}$ Our original calibration was carried out without logarithm as in Zhou (2001). We thank the anonymous referee for suggesting the use of logarithm which makes the estimation sensitive to the full range of probabilities, including those near 0 and 1 , rather than being dominated by probabilities close to 0.5 .
} 
To permit correlation $\rho$ between the returns of two asset processes, we employ the following return dynamics:

$$
\left\{\begin{array}{l}
\Delta V_{1}=V_{1}\left[\frac{\mu_{1}}{n}+\frac{\sigma_{1}}{\sqrt{n}} \times \Delta Z_{1}\right] \\
\Delta V_{2}=V_{2}\left[\frac{\mu_{2}}{n}+\frac{\rho \sigma_{1}}{\sqrt{n}} \times \Delta Z_{1}+\frac{\sqrt{1-\rho^{2}} \sigma_{2}}{\sqrt{n}} \times \Delta Z_{2}\right],
\end{array}\right.
$$

where $n$ denotes the number of time intervals partitioned for each year and $\mu_{i}$ is the net drift rate. The random variables $\Delta Z_{1}$ and $\Delta Z_{2}$ follow two independent standard normal distributions. Volatility for each period is $\sigma_{i} / \sqrt{n}$ where $\sigma_{i}$ is the annualised asset return volatility for firm $i$. For example, when the time interval is in months, $n$ is set to 12 and $\sigma_{i} / \sqrt{12}$ is the monthly asset return volatility. In each simulation, $t$ is represented by the number of time steps within the period $[0, t]$. The convergence of Monte Carlo simulations can be achieved by a large number of iterations. For each rating pair (e.g., Baa and Ba firms), we generate 10,000 sample paths. Correlations of assets, equities and debts are calculated for each sample path and then we take their averages over all the sample paths, respectively.

\section{The Hybrid Model: Results and Analysis}

In this section, we implement our hybrid model to predict default correlations and then compare our estimates with empirical default correlations and predicted default correlations by Zhou's model (2001).

\subsection{Deviation of equity correlation from asset correlation - horizon and rating effects}

As discussed at the beginning of Section 3, equity correlation may not be a good proxy for asset correlation, especially for low-rated bonds. In this section, we use the numerical evidence to show how much equity correlation could deviate from asset correlation as time horizon and credit risk change. We fix the correlation between two asset processes at $\rho=40 \%$, an ad hoc number chosen for the purpose of illustration. Table 5 reports the simulation results for the relation between asset correlation $\rho$ and equity correlation $\rho_{S}$ over the sample periods of 1970-1993 and 1990-2010, respectively.

The results show that model-predicted equity correlations increasingly deviate from asset correlation $\rho=40 \%$ as the time horizon increases and rating declines. This is due to the diffusional nature of the two asset value processes and the nonlinearity in the modelpredicted asset-equity relationship. Take the pair of Aa-Ba ratings as an example - when time horizon $T=1$ year, equity correlation is about $38 \%$ for both sample periods of 1970 1993 and 1990-2010. It is fairly close to the given asset correlation $\rho=40 \%$. But for $T=10$ years, equity correlation drops to $27.79 \%$ and $25.32 \%$ for the two sample periods, respectively. The other pairs exhibit the same trend to support the evidence that the gap between asset correlation and equity correlation widens as time horizon increases. Similarly, the gap widens as bond rating declines. For example, when $T=10$ years, equity correlation for B-B bonds drops to $17.96 \%$ and $13.18 \%$ for the two sample periods, respectively. Our numerical results strongly suggest that equity correlation is not an appropriate proxy for asset correlation, especially for risky bonds and longer time horizons. 
Table 5

The extended LT model-implied equity correlation with fixed asset correlation

This table reports the extended LT model-implied equity correlation $\rho_{S}$ (in percentages) for different credit ratings over time horizons 1 to 10 years, which is used to compare with the fixed asset correlation $\rho=40 \%$. The results are used to check the assumption of equality of equity correlation with asset correlation in Zhou's (2001) model, $\rho=\rho_{S}$ for the sample periods of 1970-1993 and 1990-2010, respectively.

Panel A: The extended LT model implied equity correlations for 1970-1993

\begin{tabular}{|c|c|c|c|c|c|}
\hline$T$ (years) & Aa-Aa & Aa-A & Aa-Baa & $\mathrm{Aa}-\mathrm{Ba}$ & Aa-B \\
\hline 1 & 38.03 & 38.53 & 38.14 & 38.48 & 37.95 \\
\hline 2 & 37.88 & 38.13 & 37.91 & 37.54 & 35.95 \\
\hline 3 & 37.67 & 37.63 & 37.11 & 36.10 & 33.76 \\
\hline 4 & 37.34 & 37.11 & 36.32 & 34.57 & 31.58 \\
\hline 5 & 37.09 & 36.60 & 35.43 & 33.13 & 29.55 \\
\hline 6 & 36.82 & 36.25 & 34.74 & 31.82 & 27.78 \\
\hline 7 & 36.64 & 35.96 & 34.11 & 30.70 & 26.22 \\
\hline 8 & 36.50 & 35.75 & 33.53 & 29.66 & 24.82 \\
\hline 9 & 36.38 & 35.57 & 32.98 & 28.63 & 23.52 \\
\hline \multirow[t]{2}{*}{10} & 36.30 & 35.41 & 32.52 & 27.79 & 22.41 \\
\hline & A-A & A-Baa & $\mathrm{A}-\mathrm{Ba}$ & A-B & Baa-Baa \\
\hline 1 & 38.38 & 38.40 & 38.14 & 38.26 & 38.40 \\
\hline 2 & 37.81 & 37.87 & 37.23 & 35.96 & 37.87 \\
\hline 3 & 36.95 & 36.82 & 35.54 & 33.50 & 36.90 \\
\hline 4 & 36.33 & 35.84 & 33.98 & 31.21 & 35.76 \\
\hline 5 & 35.81 & 34.90 & 32.54 & 28.94 & 34.70 \\
\hline 6 & 35.39 & 34.14 & 31.23 & 27.17 & 33.76 \\
\hline 7 & 35.10 & 33.47 & 30.03 & 25.61 & 32.89 \\
\hline 8 & 34.81 & 32.87 & 28.99 & 24.19 & 32.04 \\
\hline 9 & 34.59 & 32.31 & 27.98 & 22.86 & 31.29 \\
\hline \multirow[t]{2}{*}{10} & 34.40 & 31.82 & 27.11 & 21.74 & 30.66 \\
\hline & Baa-Ba & Baa-B & $\mathrm{Ba}-\mathrm{Ba}$ & $\mathrm{Ba}-\mathrm{B}$ & B-B \\
\hline 1 & 38.40 & 37.84 & 38.09 & 38.30 & 37.84 \\
\hline 2 & 37.69 & 36.31 & 36.94 & 36.00 & 35.02 \\
\hline 3 & 36.02 & 33.88 & 34.96 & 33.23 & 31.82 \\
\hline 4 & 34.38 & 31.59 & 32.94 & 30.63 & 28.91 \\
\hline 5 & 32.74 & 29.37 & 30.91 & 28.23 & 26.24 \\
\hline 6 & 31.34 & 27.53 & 29.17 & 26.28 & 24.08 \\
\hline 7 & 30.13 & 25.88 & 27.72 & 24.59 & 22.23 \\
\hline 8 & 29.00 & 24.45 & 26.34 & 23.10 & 20.62 \\
\hline 9 & 27.92 & 23.07 & 25.07 & 21.69 & 19.15 \\
\hline 10 & 26.97 & 21.95 & 24.00 & 20.48 & 17.96 \\
\hline
\end{tabular}


Table 5

Continued.

Panel B: The extended LT model implied equity correlations for 1990-2010

\begin{tabular}{lccccc}
$T$ (years) & Aa-Aa & Aa-A & Aa-Baa & Aa-Ba & Aa-B \\
\hline 1 & 39.89 & 39.71 & 39.28 & 37.93 & 36.48 \\
2 & 39.75 & 39.27 & 38.76 & 34.73 & 33.36 \\
3 & 39.55 & 38.90 & 37.99 & 32.72 & 30.55 \\
4 & 39.24 & 38.69 & 37.44 & 31.08 & 27.98 \\
5 & 39.13 & 38.69 & 37.25 & 29.74 & 26.05 \\
6 & 38.99 & 38.56 & 37.08 & 28.52 & 24.52 \\
7 & 38.97 & 38.54 & 36.88 & 27.57 & 23.25 \\
8 & 38.97 & 38.46 & 36.68 & 26.72 & 22.11 \\
9 & 38.94 & 38.34 & 36.54 & 25.93 & 21.11 \\
10 & 38.89 & 38.23 & 36.44 & 25.32 & 20.28 \\
\hline & A-A & A-Baa & A-Ba & A-B & Baa-Baa \\
\hline 1 & 39.82 & 39.19 & 37.71 & 37.28 & 38.83 \\
2 & 38.95 & 38.01 & 34.95 & 33.32 & 37.81 \\
3 & 38.30 & 37.25 & 32.49 & 30.16 & 36.95 \\
4 & 37.89 & 37.00 & 30.71 & 27.87 & 36.34 \\
5 & 37.80 & 36.67 & 29.08 & 26.02 & 35.88 \\
6 & 37.61 & 36.38 & 27.99 & 24.57 & 35.59 \\
7 & 37.36 & 36.12 & 27.00 & 23.23 & 35.29 \\
8 & 37.33 & 35.95 & 26.10 & 22.00 & 35.06 \\
9 & 37.22 & 35.81 & 25.31 & 21.04 & 34.89 \\
10 & 37.19 & 35.57 & 24.66 & 20.14 & 34.77 \\
\hline & Baa-Ba & Baa-B & Ba-Ba & Ba-B & B-B \\
\hline 1 & 37.81 & 36.60 & 36.78 & 36.39 & 35.29 \\
2 & 34.93 & 33.03 & 32.59 & 31.43 & 29.20 \\
3 & 32.76 & 29.69 & 29.15 & 27.97 & 25.25 \\
5 & 30.95 & 27.10 & 26.71 & 25.14 & 22.22 \\
6 & 29.75 & 25.26 & 24.87 & 23.00 & 19.77 \\
7 & 28.65 & 23.72 & 23.38 & 21.31 & 17.81 \\
8 & 27.54 & 22.25 & 22.26 & 19.90 & 16.31 \\
9 & 26.65 & 21.02 & 21.13 & 18.69 & 15.00 \\
\hline 0 & 25.98 & 19.98 & 20.27 & 17.59 & 14.00 \\
\hline & 25.41 & 19.04 & 19.49 & 16.63 & 13.18 \\
\hline & & & & &
\end{tabular}

\subsection{Calibrated asset correlation and default correlation predictions}

To implement our hybrid model to predict default correlations, we first infer asset correlations from empirical equity correlations obtained in Section 2.2. This is achieved by calibrating the extended LT model - we simulate the model to generate the time series of equity and asset processes through Equations (5) and (8). The two simulated time series can be used to compute equity correlation $\rho_{S}$ and asset correlation $\rho$. In each run, this 
process is iterated 2,000 to 10,000 times to ensure the convergence ${ }^{15}$ of the averages of both equity and asset correlations, respectively. Asset correlation is determined by having model-generated equity correlation match our corresponding empirical equity correlations given in Table 2. The results of the calibrated asset correlation are reported in Table 6 for different time horizons and rating pairs for the two different sample periods.

These calibrated values of asset correlation are then used as the inputs to Zhou's (2001) framework to complete the hybrid model for estimating default correlation $\rho_{D}$ reported in Table 7. Using the empirical default correlations reported in Table 1 as a benchmark, we are able to compare the performance of the hybrid model with that of Zhou's model in Table 3.

\subsection{Model performance comparison - the hybrid model vs. Zhou's (2001) model}

First, for high-rated bonds, Zhou's and the hybrid models do not differ much. Their predictions for the pairs of Aa-Aa, Aa-A and A-A are similar, especially for shorter horizons. Even for $T=10$ years, the differences are statistically insignificant. For example, for the A-A pair, the hybrid model predicts a default correlation of $4.6 \%(2.8 \%)$ in Table 7 compared to 3.6\% (2.5\%) by Zhou's model in Table 3 for 1970-1993 (1990$2010)$, while the corresponding empirical default correlation is $2 \%(3.9 \%)$ in Table 1 . For the Aa-A pair, the results are $3.0 \%(1.8 \%)$ by the hybrid model versus $2.5 \%(1.7 \%)$ by Zhou's model for 1970-1993 (1990-2010), while the empirical benchmark is $2 \%$ for both sample periods. The observation indicates that the assumption of equality of equity and asset correlations in Zhou (2001) may be valid for high-rated firms and short time horizons. As Zhou (2001) points out, for high-rated firms with the low leverage, equity and asset processes are close.

However, as rating goes down and time horizon increases, the difference between the two model estimates becomes more and more pronounced and the improvement by the hybrid model becomes more substantial. For example, for the B-A pair and $T=10$ years, the predicted default correlation is $7.5 \%(5.6 \%)$ by the hybrid model in Table 7 and $4.4 \%$ (2.9\%) by Zhou's model in Table 3 for 1970-1993 (1990-2010), which marks a significant improvement given the empirical estimate of $9 \%(10.8 \%)$ in Table 1 . The improvement is even more remarkable for the B-B pair - 38\% (32\%) as the empirical benchmark, $13.7 \%$ $(11.0 \%)$ by Zhou's model, but $32.3 \%(36.1 \%)$ by the hybrid model. In the case of the BBaa pair and $T=10$ years with the sample of $1990-2010$, we have $11.4 \%$ as the empirical benchmark (Table 1's Panel B), 5.4\% by Zhou's model (Table 3's Panel B) and $11.1 \%$ by the hybrid model (Table 7's Panel B), which is a remarkable improvement. In sum, our overall results suggest that the hybrid model outperforms Zhou's model.

Finally, the hybrid model slightly overpredicts default correlation in some cases. For example, the worst case seems to be the Ba-Ba pair, $T=10$ years with the sample of 1970-1993-the empirical estimate is 8\% in Table 1's Panel A, while the hybrid model predicts $20.7 \%$ in Table 7's Panel A. However, with the newer sample of 1990-2010, the overprediction for the Ba-Ba pair is considerably less - $17.3 \%$ (actual) versus $23 \%$ (predicted). There might be two possible reasons for the overprediction of the hybrid

\footnotetext{
${ }^{15}$ The convergence here means that two separate runs generate correlations within a range of \pm 0.005 . If the two runs yield a greater difference, we increase the iteration number. We find that, for most rating pairs, 3000 iterations are enough to achieve this criterion.
} 
Table 6

Calibrated asset correlation by the extended LT model

This table reports asset correlation implied by the observed equity correlation for different credit ratings over different time horizons for the periods of 1970-1993 and 1990-2010, respectively. The calibrated asset correlation $\rho$ (in percentage) is obtained by matching the extended LT model-implied equity correlation $\rho_{S}$ to our empirical equity correlation (in Table 2 Panel B's). Time horizons reported are 4, 6, 8 and 10 years.

Panel A: Sample period 1970-1993

\begin{tabular}{|c|c|c|c|c|c|c|c|c|c|c|}
\hline & \multicolumn{5}{|c|}{$T=4$ years } & \multicolumn{5}{|c|}{$T=6$ years } \\
\hline & $\mathrm{Aa}$ & $\mathrm{A}$ & Baa & $\mathrm{Ba}$ & $\mathrm{B}$ & $\mathrm{Aa}$ & $\mathrm{A}$ & Baa & $\mathrm{Ba}$ & $\mathrm{B}$ \\
\hline $\mathrm{Aa}$ & 27.67 & & & & & 28.06 & & & & \\
\hline A & 26.98 & 28.41 & & & & 27.62 & 29.16 & & & \\
\hline $\mathrm{Baa}$ & 25.84 & 27.14 & 25.96 & & & 27.01 & 28.49 & 27.50 & & \\
\hline $\mathrm{Ba}$ & 25.29 & 27.23 & 25.47 & 26.63 & & 27.48 & 29.63 & 27.94 & 30.07 & \\
\hline \multirow[t]{3}{*}{ B } & 26.90 & 29.49 & 28.40 & 29.20 & 32.02 & 30.58 & 33.88 & 33.11 & 34.03 & 38.44 \\
\hline & \multicolumn{5}{|c|}{$T=8$ years } & \multicolumn{5}{|c|}{$T=10$ years } \\
\hline & $\mathrm{Aa}$ & $\mathrm{A}$ & $\mathrm{Baa}$ & $\mathrm{Ba}$ & $\mathrm{B}$ & $\mathrm{Aa}$ & $\mathrm{A}$ & Baa & $\mathrm{Ba}$ & $\mathrm{B}$ \\
\hline $\mathrm{Aa}$ & 28.31 & & & & & 28.46 & & & & \\
\hline A & 28.01 & 29.65 & & & & 28.27 & 30.00 & & & \\
\hline $\mathrm{Baa}$ & 27.99 & 29.60 & 28.98 & & & 28.86 & 30.57 & 30.28 & & \\
\hline $\mathrm{Ba}$ & 29.48 & 31.91 & 30.19 & 33.30 & & 31.46 & 34.13 & 32.47 & 36.55 & \\
\hline B & 34.23 & 38.05 & 37.66 & 38.72 & 44.89 & 37.91 & 42.34 & 42.48 & 43.67 & 51.54 \\
\hline
\end{tabular}

Panel B: Sample period 1990-2010

\begin{tabular}{|c|c|c|c|c|c|c|c|c|c|c|}
\hline & \multicolumn{5}{|c|}{$T=4$ years } & \multicolumn{5}{|c|}{$T=6$ years } \\
\hline & $\mathrm{Aa}$ & A & $\mathrm{Baa}$ & $\mathrm{Ba}$ & $\mathrm{B}$ & $\mathrm{Aa}$ & A & $\mathrm{Baa}$ & $\mathrm{Ba}$ & $\mathrm{B}$ \\
\hline $\mathrm{Aa}$ & 21.59 & & & & & 21.73 & & & & \\
\hline A & 19.79 & 21.41 & & & & 19.85 & 21.57 & & & \\
\hline $\mathrm{Baa}$ & 20.08 & 21.14 & 22.53 & & & 20.28 & 21.50 & 23.01 & & \\
\hline $\mathrm{Ba}$ & 21.11 & 22.85 & 24.52 & 29.78 & & 23.00 & 25.07 & 26.49 & 34.01 & \\
\hline \multirow[t]{3}{*}{ B } & 19.72 & 21.20 & 24.84 & 29.43 & 33.66 & 22.49 & 24.05 & 28.38 & 34.73 & 41.99 \\
\hline & \multicolumn{5}{|c|}{$T=8$ years } & \multicolumn{5}{|c|}{$T=10$ years } \\
\hline & $\mathrm{Aa}$ & A & $\mathrm{Baa}$ & $\mathrm{Ba}$ & B & $\mathrm{Aa}$ & A & $\mathrm{Baa}$ & $\mathrm{Ba}$ & B \\
\hline $\mathrm{Aa}$ & 21.74 & & & & & 21.79 & & & & \\
\hline A & 19.91 & 21.73 & & & & 20.03 & 21.81 & & & \\
\hline $\mathrm{Baa}$ & 20.50 & 21.75 & 23.36 & & & 20.64 & 21.99 & 23.55 & & \\
\hline $\mathrm{Ba}$ & 24.55 & 26.88 & 28.47 & 37.64 & & 25.91 & 28.45 & 29.87 & 40.80 & \\
\hline B & 24.94 & 26.85 & 32.02 & 39.59 & 49.87 & 27.20 & 29.34 & 35.36 & 44.49 & 56.73 \\
\hline
\end{tabular}


Table 7

Default correlation predicted by the hybrid model

This table reports the default correlation estimates (in percentage) by the hybrid model for different credit ratings over different time horizons for the periods of 1970-1993 and 1990-2010, respectively. The hybrid model consists of the extended LT model and Zhou's (2001) model. The extended LT model first estimates the calibrated asset correlation based on the empirical estimates of equity correlation. The calibrated asset correlation is then input to Zhou's (2001) model to estimate default correlations. Time horizons reported are $4,6,8$ and 10 years.

Panel A: Sample period 1970-1993

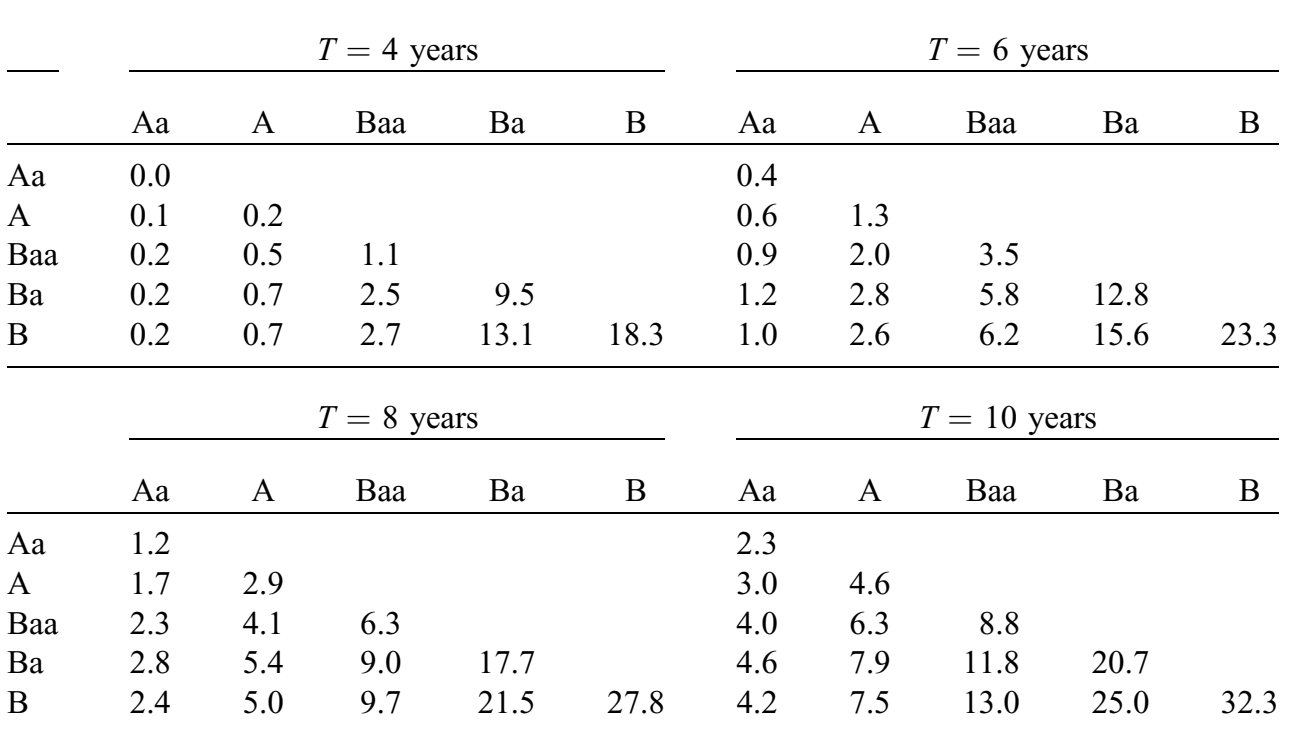

Panel B: Sample period 1990-2010

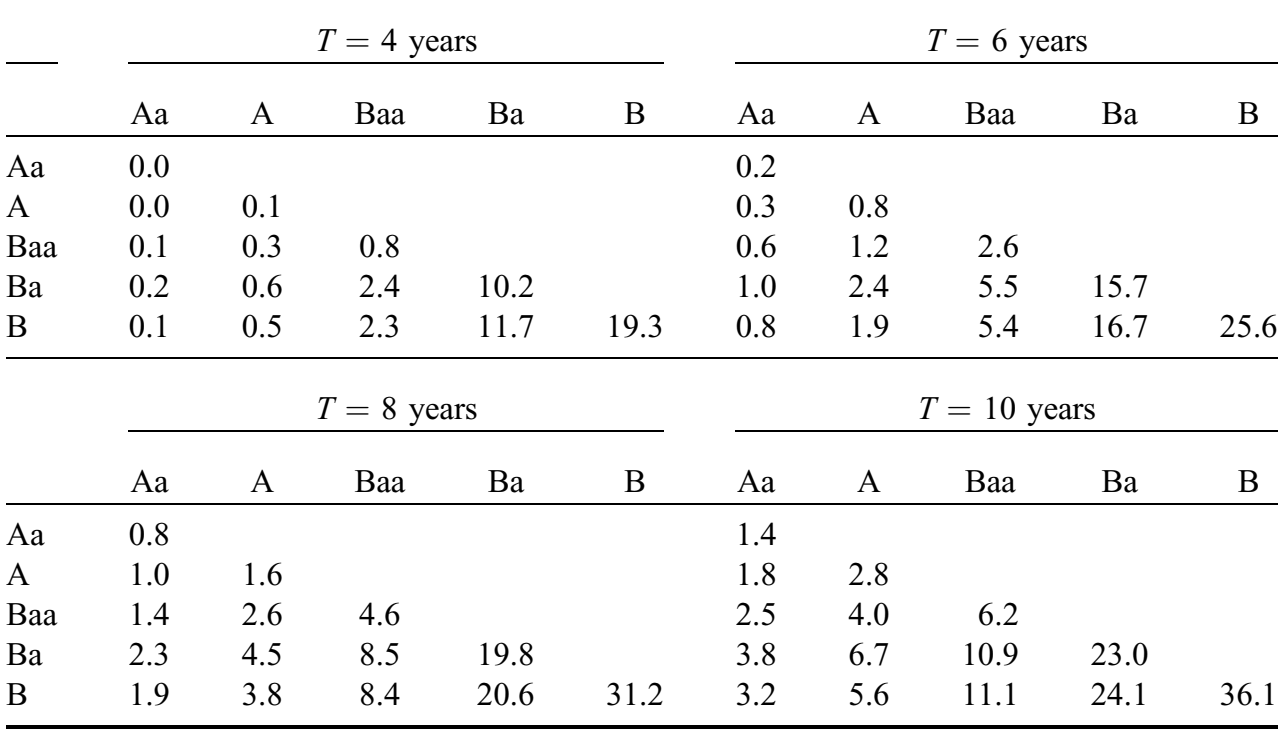


model. First, the accuracy of empirical estimation of default correlation is limited by the quality of the data. As discussed in Section 2.1, the estimation error of empirical default correlation is relatively large if the sample size is small or default events are relatively rare. In this case, the "overprediction" by the hybrid model could be attributed to the inaccurate benchmark. Second, the extended LT model and Zhou's model may not integrate well enough in our hybrid approach because of different assumptions. For example, the LT model imposes par bond condition while Zhou's model does not have this restriction. If this is the case, further modelling improvement is needed if the overprediction becomes intolerable. Nevertheless, from a risk management perspective, overprediction of default risk may cause less harm than otherwise.

Taken together, our hybrid model demonstrates noticeable improvements over the existing structural model by Zhou (2001), especially for prediction of default correlations between low-rated bonds. The results show that structural models with correct specifications can predict unobserved default correlations from the observed equity correlations more reliably and help understand the sources of default clustering better.

\subsection{Comparison of the Hybrid model with Zhou's (2001) model over the period of the 2008 financial crisis $^{16}$}

The 2008 financial crisis poses a serious challenge to risk management in practice as well as in the theoretical modelling of default correlation. In this section, we compare default correlations predicted by the hybrid model and Zhou's (2001) model over the crisis period of 2007-2009 and post-crisis 2010. The comparison is motivated by two reasons:

First, Section 4.3 compares the two model predictions with the input of the average equity correlations over two sample periods (about 20 years each). Hence, the comparison of two models over the crisis period in which equity correlations fluctuate greatly year by year (see Table 8) could complement our prior studies and apply the model in a dynamic sense.

Second, Kalemli-Ozcan et al. (2011) show that the average leverage ratio of the US firms significantly increased during the financial crisis and reached the peak in early 2008 . It went down in 2009 because of the firms' hoarding cash. This empirical evidence also provides strong motivation to compare the two models over the crisis period because Zhou's model assumes constant leverage while the LT model does not. It would be interesting to see how the theoretical differences between the two models translate into numerical differences in their predictions for the tumultuous years of the crisis.

We first estimate annual equity correlations within and across ratings for 2007 through 2010. Table 8 shows that all equity correlations in 2008 increased significantly from 2007 , decreased sharply in 2009, and then reached a peak in 2010. The results suggest that equity correlations fluctuate greatly during the crisis period. Interestingly, the trend of the change of equity correlations is similar to that of the change of firm leverages documented by Kalemli-Ozcan et al. (2011). ${ }^{17} \mathrm{Next}$, we compare the predicted default correlations by

\footnotetext{
${ }^{16}$ We thank the anonymous referee for this valuable suggestion.

${ }^{17}$ Stock return volatility over the recent crisis is also documented to have a similar oscillating pattern such as significant changes in 2008 (see Schwert, 2011). The similar pattern of stock return volatility following the crisis may be a contributing factor to a certain extent for the unstable change of stock return correlations.
} 
Table 8

Empirical estimates of equity correlation over the period of the 2008 financial crisis

This table reports the empirical estimates of equity correlation (in percentage) for different credit ratings over and post the 2008 financial crisis: 2007, 2008, 2009 and 2010, respectively. Equity correlations are calculated based on monthly stock returns of different rating firms over the sample periods.

\begin{tabular}{|c|c|c|c|c|c|c|c|c|c|c|}
\hline & \multicolumn{5}{|c|}{2007} & \multicolumn{5}{|c|}{2008} \\
\hline & $\mathrm{Aa}$ & A & $\mathrm{Baa}$ & $\mathrm{Ba}$ & $\mathrm{B}$ & $\mathrm{Aa}$ & A & Baa & $\mathrm{Ba}$ & $\mathrm{B}$ \\
\hline $\mathrm{Aa}$ & 0.20 & & & & & 0.35 & & & & \\
\hline A & 0.20 & 0.20 & & & & 0.37 & 0.40 & & & \\
\hline Baa & 0.20 & 0.20 & 0.22 & & & 0.36 & 0.39 & 0.38 & & \\
\hline $\mathrm{Ba}$ & 0.16 & 0.18 & 0.19 & 0.18 & & 0.35 & 0.39 & 0.38 & 0.40 & \\
\hline \multirow[t]{3}{*}{ B } & 0.17 & 0.19 & 0.21 & 0.20 & 0.22 & 0.29 & 0.32 & 0.32 & 0.33 & 0.29 \\
\hline & \multicolumn{5}{|c|}{2009} & \multicolumn{5}{|c|}{2010} \\
\hline & $\mathrm{Aa}$ & A & Baa & $\mathrm{Ba}$ & $\mathrm{B}$ & $\mathrm{Aa}$ & A & Baa & $\mathrm{Ba}$ & $\mathrm{B}$ \\
\hline $\mathrm{Aa}$ & 0.14 & & & & & 0.45 & & & & \\
\hline A & 0.17 & 0.18 & & & & 0.45 & 0.45 & & & \\
\hline $\mathrm{Baa}$ & 0.13 & 0.16 & 0.16 & & & 0.43 & 0.44 & 0.44 & & \\
\hline $\mathrm{Ba}$ & 0.13 & 0.18 & 0.18 & 0.23 & & 0.40 & 0.41 & 0.43 & 0.43 & \\
\hline B & 0.11 & 0.15 & 0.16 & 0.21 & 0.20 & 0.35 & 0.37 & 0.40 & 0.41 & 0.40 \\
\hline
\end{tabular}

the two models over the crisis period of 2007-2009 and post-crisis 2010 using the observed equity correlations given in Table 8 . To highlight the differences, we provide results for both 1 -year and 5 -year horizons in Table 9 . Since investment-grade bonds have extremely low default probabilities over a short horizon (such as 1 year), the default correlation is practically zero as predicted by both models. Hence, we only report default correlations among junk bonds for a 1-year period in Panel A. As shown, the difference of default correlations predicted by the two models is noticeable over the crisis period. For example, the 1-year default correlation for B-B pair in 2008 (the peak of the crisis) is $7.85 \%$ by Zhou's (2001) model versus $8.49 \%$ by the hybrid model. The difference is 64 basis points. However, the difference between the two models is not static, which is 42 and 35 basis points in 2007 and 2009, respectively. The difference jumps to 113 basis points post crisis in 2010. Panel B shows a similar trend for the 5 -year horizon, while the magnitude of the difference is larger. If we still use B-B pair as an example, the default correlation predicted by the hybrid model is $7.19 \%, 9.97 \%, 6.4 \%$, and $15.19 \%$ higher than that predicted by Zhou's (2001) model for 2007 through 2010, respectively.

Taken together, the comparison between the two models during and after the crisis period indicates that our model improvement over Zhou's model is not a simple adjustment that could be captured by a constant. The dramatic change of equity correlations over this abnormal period provides a unique opportunity to highlight the theoretical improvement of the hybrid model over Zhou's model, especially in the domain of low credit ratings. 
Table 9

Default correlation predicted by the hybrid and Zhou's models over the period of the 2008 financial crisis

This table reports the default correlation estimates (in percentage) for different credit ratings by the hybrid and Zhou's models based on equity correlations observed in 2007, 2008, 2009 and 2010, respectively. Panel A reports 1-year predicted default correlations and Panel B reports 5-year predicted default correlations. For 1-year horizon, we only report speculative ratings because investment-grade ratings have values equal or very close to zero due to their extremely low short-term default probabilities, and thereby the difference between the two models is practically unnoticeable.

Panel A: 1-year Horizon

Default correlation predicted by Zhou's (2001) model

\begin{tabular}{|c|c|c|c|c|c|c|c|c|}
\hline & \multicolumn{2}{|c|}{2007} & \multicolumn{2}{|c|}{2008} & \multicolumn{2}{|c|}{2009} & \multicolumn{2}{|c|}{2010} \\
\hline & $\mathrm{Ba}$ & $\mathrm{B}$ & $\mathrm{Ba}$ & B & $\mathrm{Ba}$ & B & $\mathrm{Ba}$ & B \\
\hline $\mathrm{Ba}$ & 0.16 & & 1.37 & & 0.28 & & 1.69 & \\
\hline B & 0.80 & 5.38 & 1.80 & 7.85 & 0.86 & 4.71 & 2.62 & 12.55 \\
\hline
\end{tabular}

Default correlation predicted by the hybrid model

\begin{tabular}{|c|c|c|c|c|c|c|c|c|}
\hline & \multicolumn{2}{|c|}{2007} & \multicolumn{2}{|c|}{2008} & \multicolumn{2}{|c|}{2009} & \multicolumn{2}{|c|}{2010} \\
\hline & $\mathrm{Ba}$ & B & $\mathrm{Ba}$ & B & $\mathrm{Ba}$ & B & $\mathrm{Ba}$ & B \\
\hline $\mathrm{Ba}$ & 0.18 & & 1.61 & & 0.32 & & 2.00 & \\
\hline B & 0.85 & 5.80 & 1.94 & 8.49 & 0.92 & 5.06 & 2.83 & 13.68 \\
\hline
\end{tabular}

Panel B: 5-year Horizon

Default correlation predicted by Zhou's (2001) model

\begin{tabular}{|c|c|c|c|c|c|c|c|c|c|c|}
\hline & \multicolumn{5}{|c|}{2007} & \multicolumn{5}{|c|}{2008} \\
\hline & $\mathrm{Aa}$ & $\mathrm{A}$ & $\mathrm{Baa}$ & $\mathrm{Ba}$ & $\mathrm{B}$ & $\mathrm{Aa}$ & $\mathrm{A}$ & $\mathrm{Baa}$ & $\mathrm{Ba}$ & $\mathrm{B}$ \\
\hline $\mathrm{Aa}$ & 0.06 & & & & & 0.34 & & & & \\
\hline A & 0.11 & 0.26 & & & & 0.70 & 1.62 & & & \\
\hline $\mathrm{Baa}$ & 0.22 & 0.58 & 1.51 & & & 0.90 & 2.39 & 4.50 & & \\
\hline $\mathrm{Ba}$ & 0.28 & 0.91 & 2.67 & 6.84 & & 0.83 & 2.62 & 6.78 & 9.00 & \\
\hline \multirow[t]{3}{*}{ B } & 0.29 & 0.95 & 2.96 & 8.95 & 12.80 & 0.48 & 1.55 & 4.55 & 15.16 & 17.11 \\
\hline & \multicolumn{5}{|c|}{2009} & \multicolumn{5}{|c|}{2010} \\
\hline & $\mathrm{Aa}$ & A & $\mathrm{Baa}$ & $\mathrm{Ba}$ & $\mathrm{B}$ & $\mathrm{Aa}$ & A & Ваa & $\mathrm{Ba}$ & $\mathrm{B}$ \\
\hline $\mathrm{Aa}$ & 0.02 & & & & & 0.93 & & & & \\
\hline A & 0.08 & 0.23 & & & & 1.39 & 2.42 & & & \\
\hline $\mathrm{Baa}$ & 0.11 & 0.40 & 0.94 & & & 1.46 & 3.31 & 6.26 & & \\
\hline $\mathrm{Ba}$ & 0.21 & 0.90 & 2.52 & 9.00 & & 0.98 & 2.88 & 7.94 & 19.38 & \\
\hline B & 0.18 & 0.74 & 2.30 & 9.41 & 11.50 & 0.56 & 1.79 & 5.65 & 19.09 & 24.12 \\
\hline
\end{tabular}


Table 9

Continued.

Default correlation predicted by the hybrid model

\begin{tabular}{|c|c|c|c|c|c|c|c|c|c|c|}
\hline & \multicolumn{5}{|c|}{2007} & \multicolumn{5}{|c|}{2008} \\
\hline & $\mathrm{Aa}$ & A & $\mathrm{Baa}$ & $\mathrm{Ba}$ & $\mathrm{B}$ & $\mathrm{Aa}$ & $\mathrm{A}$ & $\mathrm{Baa}$ & $\mathrm{Ba}$ & $\mathrm{B}$ \\
\hline $\mathrm{Aa}$ & 0.07 & & & & & 0.45 & & & & \\
\hline A & 0.14 & 0.32 & & & & 0.94 & 2.31 & & & \\
\hline $\mathrm{Baa}$ & 0.28 & 0.76 & 1.94 & & & 1.24 & 3.38 & 6.18 & & \\
\hline $\mathrm{Ba}$ & 0.36 & 1.19 & 3.46 & 9.24 & & 1.06 & 3.46 & 9.04 & 25.32 & \\
\hline \multirow[t]{3}{*}{ B } & 0.39 & 1.32 & 4.07 & 11.77 & 19.99 & 0.61 & 2.01 & 6.09 & 20.07 & 27.08 \\
\hline & \multicolumn{5}{|c|}{2009} & \multicolumn{5}{|c|}{2010} \\
\hline & $\mathrm{Aa}$ & A & Baa & $\mathrm{Ba}$ & $\mathrm{B}$ & $\mathrm{Aa}$ & A & Baa & $\mathrm{Ba}$ & $\mathrm{B}$ \\
\hline $\mathrm{Aa}$ & 0.03 & & & & & 1.29 & & & & \\
\hline A & 0.09 & 0.29 & & & & 1.94 & 3.52 & & & \\
\hline $\mathrm{Baa}$ & 0.13 & 0.51 & 1.17 & & & 2.04 & 4.78 & 8.79 & & \\
\hline $\mathrm{Ba}$ & 0.27 & 1.18 & 3.26 & 12.29 & & 1.22 & 3.78 & 10.60 & 27.77 & \\
\hline B & 0.24 & 1.03 & 3.18 & 12.37 & 17.90 & 0.67 & 2.22 & 7.38 & 25.36 & 39.31 \\
\hline
\end{tabular}

\section{Conclusion}

Default correlation information is important for credit analysis and risk management, but since bankruptcy is a onetime event, this makes it difficult to obtain a default correlation measure. Existing structural models rely on asset correlation to predict default correlation. Because asset correlations are unobservable, equity correlations are often used as substitutes.

In this paper, we conduct the analysis of default correlation in an integrated approach from both theoretical and empirical perspectives over the two sample periods, 1970-1993 and 1990-2010. We show that equity correlation becomes a poor approximation for asset correlation, as the time horizon lengthens and credit rating deteriorates. Our finding confirms the views of Lopez (2004) and de Servigny and Renault (2004). In order to establish a more accurate link between unobservable asset correlation and observable equity correlation and a link between asset correlation and default correlation, we propose a hybrid model that is an integration of the extended LT model in a two-firm setting with Zhou's (2001) default correlation model.

Our empirical study consistently shows that, compared to the empirical default correlations over the two different sample periods, the hybrid model demonstrates a clear improvement over Zhou's original model in predicting default correlations, especially for risky bonds where concerns for default correlation and default risk are most relevant. We also extend our investigation to the period of the recent financial crisis and find that the improvement of our hybrid model over Zhou's model is not a simple adjustment. Our hybrid model not only bridges a theoretical gap, but also has practical value. 
Finally, our results suggest that with only one basic correlated stochastic factor, i.e. the stochastic asset process, ${ }^{18}$ the hybrid model can yield reasonable predicted default correlations without relying on more complex structures, such as correlated default thresholds, incomplete information, cross holdings among firms, or nonparametric measures of correlation. As such, our hybrid model is relatively easy to implement and makes dynamic credit risk management feasible because the required inputs to the model are readily accessible equity data. Our hybrid model hence provides a useful tool for enhancing credit risk management in practice.

\section{Appendix: Joint Default Probabilities in Zhou's Model}

This appendix summarises the joint default probabilities in Zhou's model (see Zhou, 2001). When debt and equity have equal expected growth rates, i.e., leverage ratios $l_{1}$ and $l_{2}$ are constant, the expected default probability is

$$
E\left[\omega_{i}(T)=1\right]=P\left[\omega_{i}(T)=1\right]=2 \times \Phi\left(-\frac{\ln \left(V_{i, 0} / V_{B i}\right)}{\sigma_{i} \sqrt{T}}\right)=2 \times \Phi\left(-\frac{Z_{i}}{\sqrt{T}}\right)
$$

with properties

$$
\begin{aligned}
& \operatorname{var}\left[\omega_{i}(T)\right]=P\left[\omega_{i}(T)=1\right]\left\{1-P\left[\omega_{i}(T)=1\right]\right\}=E\left[\omega_{i}(T)=1\right]\left\{1-E\left[\omega_{i}(T)=1\right]\right\}, \\
& \text { and } Z_{i}=\frac{\ln V_{i, 0}-\ln V_{B i}}{\sigma_{i}}
\end{aligned}
$$

where $\Phi(\cdot)$ is cumulative normal distribution, $\sigma_{i}$ is the volatility of asset return of firm $i$, $V_{B i}$ is the default threshold for firm $i$ at time zero, $V_{i, 0}$ is the starting value of firm $i, E[\cdot]$ is unconditional expectation operator, and $\omega(T)$ is a Bernoulli random variable with $\omega$ $(T)=1$ if default happens before time horizon $T$ and $\omega(T)=0$ otherwise. The joint default probability is

$$
E\left[\omega_{1}(T) \times \omega_{2}(T)\right]=E\left[\omega_{1}(T)\right]+E\left[\omega_{2}(T)\right]-P\left[\omega_{1}(T)=1 \text { or } \omega_{2}(T)=1\right]
$$

where $P\left[\omega_{1}(T)=1\right.$ or $\left.\omega_{2}(T)=1\right]$ is the probability when at least one firm has defaulted and is given by

$$
\begin{array}{r}
P\left[\omega_{1}(T)=1 \text { or } \omega_{2}(T)=1\right]=1-\frac{1}{\alpha T} e^{\beta_{1} x_{1}+\beta_{2} x_{2}+\beta_{t} T} \\
\sum_{n=1}^{\infty} \sin \left(\frac{n \pi \theta_{o}}{\alpha}\right) e^{-\frac{\xi_{o}^{2}}{2 t}} \int_{0}^{\alpha} \sin \left(\frac{n \pi \theta}{\alpha}\right) g_{n}(\theta) d \theta .
\end{array}
$$

\footnotetext{
${ }^{18}$ Equity process is derived from asset process and thus, is not an independent process.
} 
The relevant parameters are given as follows:

$\alpha=\left\{\begin{array}{ll}\tan ^{-1}\left(-\frac{\left.\sqrt{1-\rho^{2}}\right)}{\rho}\right) & \text { if } \rho<0 \\ \pi+\tan ^{-1}\left(-\frac{\sqrt{1-\rho^{2}}}{\rho}\right) & \text { otherwise, }\end{array} \theta_{o}= \begin{cases}\tan ^{-1}\left(\frac{Z_{2} \sqrt{1-\rho^{2}}}{Z_{1}-\rho Z_{2}}\right) & \text { if } \rho<0 \\ \pi+\tan ^{-1}\left(\frac{Z_{2} \sqrt{1-\rho^{2}}}{Z_{1}-\rho Z_{2}}\right) & \text { otherwise, }\end{cases}\right.$

$g_{n}(\theta)=\int_{0}^{\infty} \xi e^{-\frac{\xi^{2}}{2 t}} e^{\xi\left[h_{1} \sin (\theta-\alpha)-h_{2} \cos (\theta-\alpha)\right]} I_{\frac{n \pi}{\alpha}}\left(\frac{\xi \xi_{o}}{t}\right) d \xi, \xi_{o}=\frac{Z_{2}}{\sin \left(\theta_{o}\right)}, \beta_{1}=\frac{\mu_{2} \rho \sigma_{1}-\mu_{1} \sigma_{2}}{\left(1-\rho^{2}\right) \sigma_{1}^{2} \sigma_{2}}$,

$\beta_{2}=\frac{\mu_{1} \rho \sigma_{2}-\mu_{2} \sigma_{1}}{\left(1-\rho^{2}\right) \sigma_{1}^{2} \sigma_{2}}, \beta_{t}=\frac{\beta_{1}^{2} \sigma_{1}^{2}}{2}+\rho a_{1} a_{2} \sigma_{1} \sigma_{2}+\frac{\beta_{2}^{2} \sigma_{2}^{2}}{2}+\beta_{1} \mu_{1}+\beta_{2} \mu_{2}$

$h_{1}=\beta_{1} \sigma_{1}+\rho \sigma_{1} \sigma_{2}, h_{2}=\beta_{2} \sigma_{2} \sqrt{1-\rho^{2}}$,

where $\rho$ is the correlation coefficient between the two firms' asset processes, $\mu_{1}$ and $\mu_{2}$ are their drift rates, $I_{\mathrm{v}}($.$) is the modified Bessel function I$ with order $\mathrm{v}$, and $\xi$ is the integrating variable for the modified Bessel function.

Finally, the default correlation coefficient $\rho_{D}$ can be calculated using the following equation,

$$
\begin{aligned}
\rho_{D} & =\frac{E\left[\omega_{1}(T) \times \omega_{2}(T)\right]-E\left[\omega_{1}(T)\right] \times E\left[\omega_{2}(T)\right]}{\sqrt{\operatorname{Var}\left[\omega_{1}(T)\right] \times \operatorname{Var}\left[\omega_{2}(T)\right]}} \\
& =\frac{E\left[\omega_{1}(T)\right]+E\left[\omega_{2}(T)\right]-P\left[\omega_{1}(T)=1 \text { or } \omega_{2}(T)=1\right]-E\left[\omega_{1}(T)\right] \times E\left[\omega_{2}(T)\right]}{\sqrt{E\left[\omega_{1}(T)=1\right]\left\{1-E\left[\omega_{1}(T)=1\right]\right\} \times E\left[\omega_{2}(T)=1\right]\left\{1-E\left[\omega_{2}(T)=1\right]\right\}}} .
\end{aligned}
$$

\section{References}

Andrade, G. and Kaplan, S., 'How costly is financial (not economic) distress? Evidence from highly levered transactions that became distressed', Journal of Finance, Vol. 53, (1998). pp. 1443-93.

Bhandari, C., 'Debt/equity ratio and expected common stock returns: empirical evidence', Journal of Finance, Vol. 43, (1988). pp. 507-28.

Black, F. and Cox, J. C., 'Valuing corporate securities: some effects of bond indenture provisions', Journal of Finance, Vol. 31, (1976). pp. 351-67.

Brennan, M. J. and Schwartz, E. S., 'Corporate income taxes, valuation, and the problem of optimal capital structure', Journal of Business, Vol. 51, (1978). pp. 103-14.

Das, S. R., Fong, G. and Geng, G., 'Impact of correlated default risk on credit portfolios (Digest Summary)', Journal of Fixed Income, Vol. 11, (2001). pp. 9-19.

de Servigny, A. and Renault, O., Measuring and Managing Credit Risk. (The McGraw-Hill Companies. (2004).).

Finger, C. C., 'Conditional approaches for CreditMetrics portfolio distributions', Credit Metrics Monitor, 2(1), (1999). pp. 13-33.

Fons, J., 'Using default rates to model the tem structures of credit risk', Financial Analyst Journal, Vol. 50, (1994). pp. 25-32. 
Gersbach, H. and Lipponer, A., 'Firm defaults and the correlation effect', European Financial Management, Vol. 9, (2003). pp. 361-77.

Giesecke, K., 'Successive correlated defaults: pricing trends and simulation', Computing in Economics and Finance 2003, Society for Computational Economics.

Giesecke, K., 'Default and information', Journal of Economic Dynamics and Control, Vol. 30, (2006). pp. 2281-2303.

Gorton, G., 'The subprime panic', European Financial Management, Vol. 15, (2009). pp. 10-46.

Huang, J. and Huang, M., 'How much of the corporate-Treasury yield spread is due to credit risk?' Working Paper (Penn State University and Cornell University, 2003).

Jorion, P., 'Risk management lessons from the credit crisis', European Financial Management, Vol. 15, (2009). pp. 923-933.

Kalemli-Ozcan, S., Sorensen, B. and Yesiltas, S., 'Leverage across firms, banks and countries', proceedings, the 2010 and 2011 Bretton Woods meetings of the NBER-MIT Global Financial Crisis Conference.

Leland, H. E. and Toft, K. B., 'Optimal capital structure, endogenous bankruptcy and the term structure of credit spreads', Journal of Finance, Vol. 50, (1996). pp. 789-819.

Lopez, J. A., 'The empirical relationship between average asset correlation, firm probability of default, and asset size', Journal of Financial Intermediation, Vol. 13, (2004). pp. 265-83.

Lucas, D. J., 'Default correlation and credit analysis', Journal of Fixed Income, Vol. 4, (1995). pp. $76-87$.

Merton, R. C., 'On the pricing of corporate debt: the risk structure of interest rates', Journal of Finance, Vol. 29, (1974). pp. 449-470.

Schwert, G. W., 'Stock volatility during the recent financial crisis', European Financial Management, Vol. 17, (2011). pp. 789-805.

Zhou, C., 'An analysis of default correlations and multiple defaults', The Review of Financial Studies, Vol. 14, (2001). pp. 555-76. 